\title{
Massive die-offs of freshwater bivalves as resource pulses
}

\author{
Ronaldo Sousa $^{1,2 *}$, Simone Varandas ${ }^{3}$, Rui Cortes ${ }^{3}$, Amílcar Teixeira ${ }^{4}$, Manuel Lopes-Lima ${ }^{2,5}$, \\ Jorge Machado ${ }^{2,5}$ and Lúcia Guilhermino ${ }^{2,5}$ \\ ${ }^{1}$ CBMA - Centre of Molecular and Environmental Biology, Department of Biology, University of Minho, Campus de Gualtar, \\ 4710-057 Braga, Portugal \\ ${ }^{2}$ CIMAR-LA/CIIMAR - Centre of Marine and Environmental Research, Laboratory of Ecotoxicology and Ecology, University \\ of Porto, Rua dos Bragas 289, 4050-123 Porto, Portugal \\ ${ }^{3}$ Forestry Department, CITAB-UTAD - Centre for Research and Technology of Agro-Environment and Biological Sciences, \\ University of Trás-os-Montes and Alto Douro, Apartado 1013, 5001-811 Vila Real, Portugal \\ ${ }^{4}$ CIMO-ESA-IPB - Mountain Research Centre, School of Agriculture, Polytechnic Institute of Bragança, Campus de Santa \\ Apolónia, Apartado 1172, 5301-854 Bragança, Portugal \\ 5 ICBAS - Instituto de Ciências Biomédicas de Abel Salazar, Universidade do Porto, Largo Prof. Abel Salazar, 2, 4099-003 Porto, \\ Portugal
}

Received 19 June 2011; Accepted 1 November 2011

\begin{abstract}
The winter of 2009/2010 was particularly severe in Northern Portugal resulting in higher river flow levels. A study was undertaken to assess the impact of this situation on several populations of freshwater bivalves (e.g., Anodonta anatina, Corbicula fluminea, Margaritifera margaritifera, Potomida littoralis and Unio delphinus) in the catchments of the Rivers Minho, Douro, Tâmega, Tua and Sabor. Massive die-offs occurred for all species in all rivers, resulting in the removal of great numbers and biomass from the riverbed to the adjacent riverbanks, reaching maximum values of 2280 individuals. $\mathrm{m}^{-2}$ and $10225 \mathrm{~g}$ wet weight.m ${ }^{-2}$, respectively. The invasive Asian clam $C$. fluminea had both highest density and biomass (however, this invasive bivalve is not dominant in several surveyed sites, and some rivers are still not colonized by this species). Results show that the quantitative and qualitative importance of this carrion transfer to the riverbank should be incorporated in future studies on the assessment of ecosystem function, contributing to a better understanding of the role of freshwater bivalves as resource pulses in adjacent terrestrial habitats. Some of the affected species have conservational importance and these extreme climatic events are predicted to increase in the future. These massive die-off events should be incorporated into management plans and selected restoration measures such as rapid relocation of endangered native mussels back to the riverbed can be easily applied to lessen possible impacts.
\end{abstract}

Key words: Corbicula fluminea / ecosystem functioning / floods / resource pulses / unionoid mussels

\section{Introduction}

Floods are important drivers of ecological change that can significantly alter the aquatic biota (Ward, 1998; Adis and Junk, 2002; Lytle and Poff, 2004). Major floods can be responsible for important alterations in the riverbed, scouring and washing away aquatic/riparian vegetation and increasing the drift of aquatic organisms (Dodds, 2002). This situation can affect human and animal health, increase chemical pollution, degrades soils and impact agriculture and farming (Wetzel, 2001). Economic losses as a consequence of these events are usually high, often resulting in important costs in human lives.

Although spatial and temporal variation are widely recognized to be fundamental attributes of natural

\footnotetext{
*Corresponding author: ronaldo.sousa@ciimar.up.pt
}

systems, scientists are only just beginning to integrate rare, but major events such as floods into ecological assessments. Little attention has been paid to researching flood impacts on biota; systematic studies are still rare due to the obvious difficulties associated with predicting these events and the collection of data, complicating the analysis of short- and long-term effects (Hering et al., 2004; Ilg et al., 2009). Studies quantifying the material transported by physical processes such as floods from aquatic to adjacent terrestrial habitats are even rarer. This transboundary resource flux can influence food webs in both terrestrial and aquatic habitats with marked changes in primary and secondary productivity and biodiversity (Polis et al., 1997; Anderson et al., 2008; Romanuk and Levings, 2010).

In freshwater ecosystems, more attention has been paid to the transport of organic and inorganic materials such as 
terrestrial invertebrates, nutrients, leaves, sediments and woody debris from the terrestrial to the aquatic areas (Polis et al., 1997). More attention is now being paid to the transport of resources from aquatic to terrestrial areas with most studies emphasizing the importance of emergent insects for terrestrial ecosystems (Baxter et al., 2005; Burdon and Harding, 2008; Gratton and Vander Zanden, 2009). Recent studies in food web dynamics highlight the importance of resource pulses at the individual, population, community and ecosystem levels (Yang, 2004; Holt, 2008) and the significance of this research topic in freshwater systems. Examples of rare episodic events of extreme resource abundance (Ostfeld and Keesing, 2000; Anderson et al., 2008; Yang et al., 2008) include massive production of flowers, fruits and seeds, synchronous emergence of arthropods, outbreaks of large numbers of small mammals and insects, mass input of carcasses, dung or urine, synchronous coral spawning and stormdriven runoff from terrestrial to aquatic systems. Such processes have been poorly documented in freshwater ecosystems, with the exception of post-spawning mortality events of anadromous fishes such as salmonids (BenDavid et al., 1998; Helfield and Naiman, 2001; Gende et al., 2002).

Extreme climatic events are predicted to increase in the near future. Major floods can be responsible for mass mortalities of aquatic species, including freshwater bivalves (Hastie et al., 2001). Freshwater bivalves are an important faunal group in aquatic ecosystems, responsible for important trophic and non-trophic functions (a food resource for higher trophic levels, parasites of fishes, reducing turbidity, nutrient recycling and creating habitats for other benthic species (Vaughn and Taylor, 1999; Strayer et al., 1994, 2004; Strayer, 2006; Vaughn, 2010). Given the various key roles of freshwater bivalves in aquatic ecosystems, it is important to assess the effects of changes in density and biomass resulting from extreme climatic events.

The severe winter of 2009/2010 provided us with an ideal opportunity to assess the mortality of different freshwater bivalve species in five river basins on the Iberian Peninsula (Rivers Minho, Douro, Tâmega, Tua and Sabor). The principal aims of this study were to determine mortality in terms of density and biomass of several freshwater bivalve species, namely Anodonta anatina (Linnaeus, 1758), Corbicula fluminea (Müller, 1774), Margaritifera margaritifera (Linnaeus, 1758), Potomida littoralis (Cuvier, 1798) and Unio delphinus (Spengler, 1793) and to discuss the possible ecological implications of this carrion as a resource pulse.

\section{Material and methods}

\section{Study area}

The surveyed area covers the two major river catchments located in Northern Portugal, the Rivers Minho and Douro (the Rivers Tâmega, Tua and Sabor are sub catchments of the Douro catchment). The River Minho (area $17080 \mathrm{~km}^{2}$ and a total length of $300 \mathrm{~km}$ ) has generally good environmental conditions, although there are some problems related to the introduction of invasive species (Sousa et al., 2008c). The River Douro (area $97603 \mathrm{~km}^{2}$ and a total length of $895 \mathrm{~km}$ ) flows westward across Spain and Northern Portugal. Both river systems are international with $95 \%$ of the Minho catchment area situated in Spain. The Portuguese area of the Douro basin (19.1\% of the total area) has a more irregular annual flow, but is highly regulated by several dams. The main impacts on the Douro basin are (i) urban, with major conurbations situated along the final kilometres that negatively affect water quality and (ii) the presence of several dams, resulting in habitat fragmentation, loss of connectivity and flow regulation. The main Portuguese tributaries of the River Douro such as Rivers Tâmega, Tua and Sabor are much smaller and deeply incised, flowing through gorges before entering the River Douro. The River Tâmega (area $3309 \mathrm{~km}^{2}$ and a total length of $140 \mathrm{~km}$ ) receives some pollution and some areas are affected by the extraction of inerts. The River Tua has a total area of $3813 \mathrm{~km}^{2}\left(690 \mathrm{~km}^{2}\right.$ in Spain and $3123 \mathrm{~km}^{2}$ in Portugal) and a total length of $106 \mathrm{~km}$. The River Sabor (area $3868 \mathrm{~km}^{2}, 555 \mathrm{~km}^{2}$ are located in Spain), flows in a North-South direction and is approximately $112 \mathrm{~km}$ long. The latter two rivers are in good environmental condition due to low levels of human pressure, although there are some problems of organic pollution in downstream areas of the River Tua.

\section{Sampling strategy and data analysis}

Data from the Portuguese National Water Institute (INAG) provided information on monthly cumulative river flow from 1990 onwards for the Rivers Minho (Foz do Mouro hydrometric station), Douro (Poçinho hydrometric station) and Tâmega (Torrão hydrometric station). We calculated the mean monthly cumulative values for the last 20 years as a proxy for a normal year and we check for possible differences in the mean monthly cumulative river flow for the different rivers between December 2009 and May 2010 and mean monthly cumulative values from December to May along the last 20 years.

A total of 31 sites were sampled along the banks of the five rivers (Fig. 1). Sites were chosen for ease of access to the riverbanks and to cover the maximum possible length of each river under study. Five sites were sampled along the River Minho, from the international upstream section to the estuarine area to avoid possible bias in the mortality values due to reasons other than flood. Only two sites were surveyed on the River Douro since this river is highly regulated. On the River Tâmega, two sites were sampled in the main channel plus three sites along two tributaries (Rivers Terva and Beça). A total of 13 sites were surveyed along the River Tua; seven were located along the River Rabaçal and two along the River Tuela. Six sites were sampled in downstream and upstream sections of the River Sabor. All samplings were carried out during May 


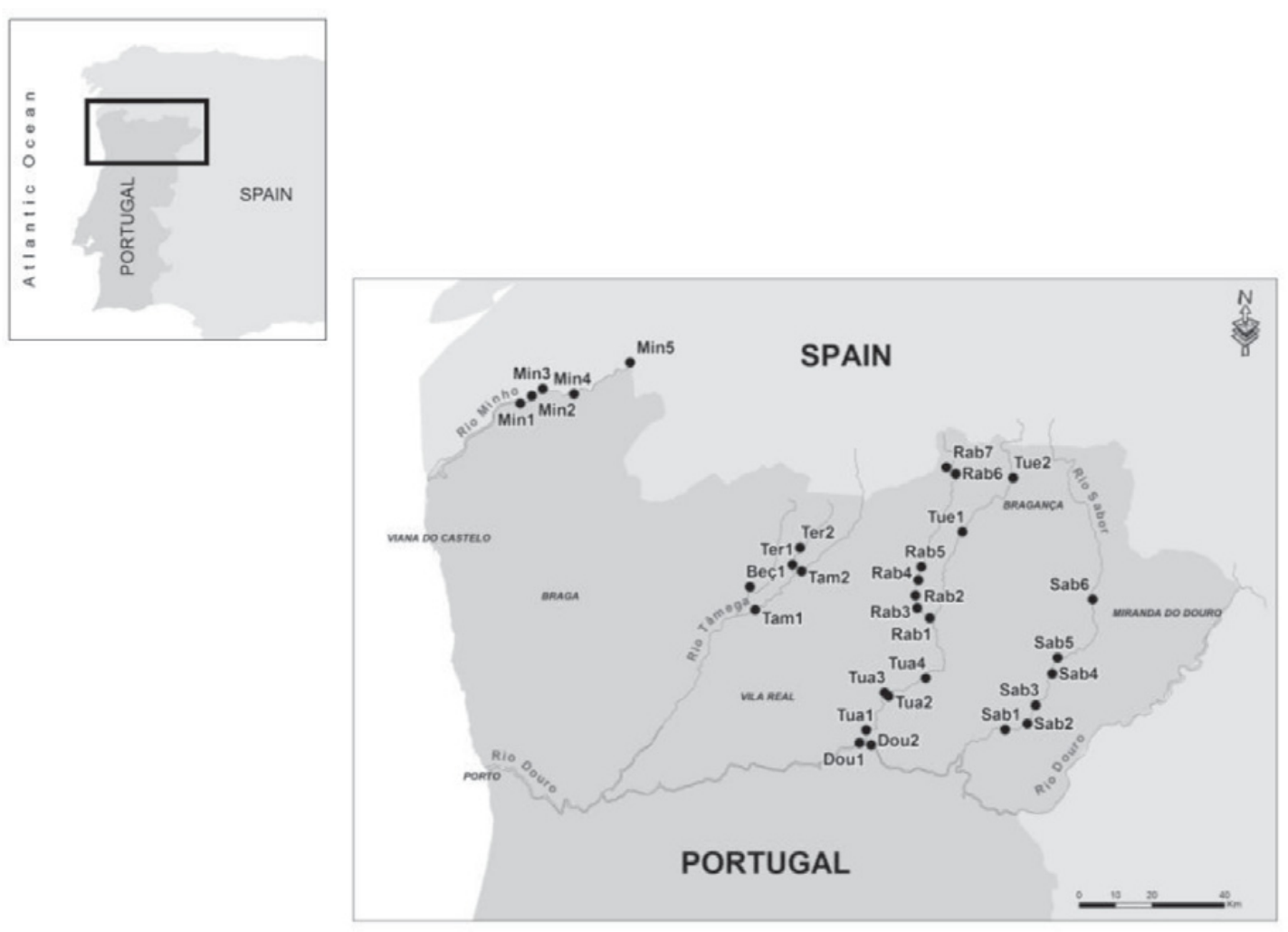

Fig. 1. Map showing sampling site locations.

and June 2010 after the return of normal flow conditions (the end of April during 2010). Depending on bivalve density, one of three sampling methods was used at each site: (i) 62 quadrats with an area of $0.25 \mathrm{~m}^{2}, 60$ of which were randomly located and the remaining two were placed on areas with maximum density (determined visually); (ii) where density levels were very low, a minimum of three people walked and searched selected areas containing deposits of dead shells, collecting all individuals encountered during a minimum of $1 \mathrm{~h}$; and (iii) at some sites we combined the two described collecting strategies using quadrats to assess the density and biomass of $C$. fluminea and surveying the whole area to assess the density and biomass of $A$. anatina, M. margaritifera, $P$. littoralis and $U$. delphinus. Detailed information on site location, methodologies and total area surveyed is given in Table 1.

The area surveyed was estimated for each site and all dead shells were collected, measured and identified to species. Collected fragments of shells and old shells that we could not confidently identify as being washed away on that year (i.e., with no periostracum) were excluded from analyses.

Biomass was determined by length-wet weight relationships of live specimens of each species collected between May and June 2010 from each river system. Differences in the bivalve composition between rivers were assessed using ANOSIM (PRIMER package; Clarke and Warwick, 2001).

\section{Results}

Historical data of the cumulative river flows measured at the Rivers Minho, Douro and Tâmega between October 2009 and September 2010 and mean monthly values for the last 20 years are given in Figure 2. Comparison of cumulative river flows measured between December 2009 and May 2010 and mean values from the 20 year data set (comprising values from December to May) reveal a clearly higher cumulative river flow during the 2009/2010 period in the Rivers Minho $(F=5.19, P<0.05)$, Douro $(F=3.95, \quad P<0.05)$ and Tâmega $(F=4.45, \quad P<0.05)$. No data were available for the Rivers Tua and Sabor. Despite the fact that both the Rivers Tua and Sabor have lower flow levels than the other rivers; based on expert opinion we concluded that a pattern of increased flow during 2009/2010 also occurred in these systems. Since both of these rivers are much less affected by regulation, it is actually possible that this pattern was even more marked than in the other rivers under study. Therefore, rivers in northern Portugal exhibited higher flow during the winter of $2009 / 2010$ and early spring 2010 and we can consider 2009/2010 as an unusual year in terms of river flow.

A total of five bivalve species (A. anatina, C. Aluminea, $M$. margaritifera, $P$. littoralis and $U$. delphinus) were transported from the riverbed to adjacent riverbanks, where they were subject to desiccation and subsequent death (Figs. 3a and b). On the River Minho, we collected three 


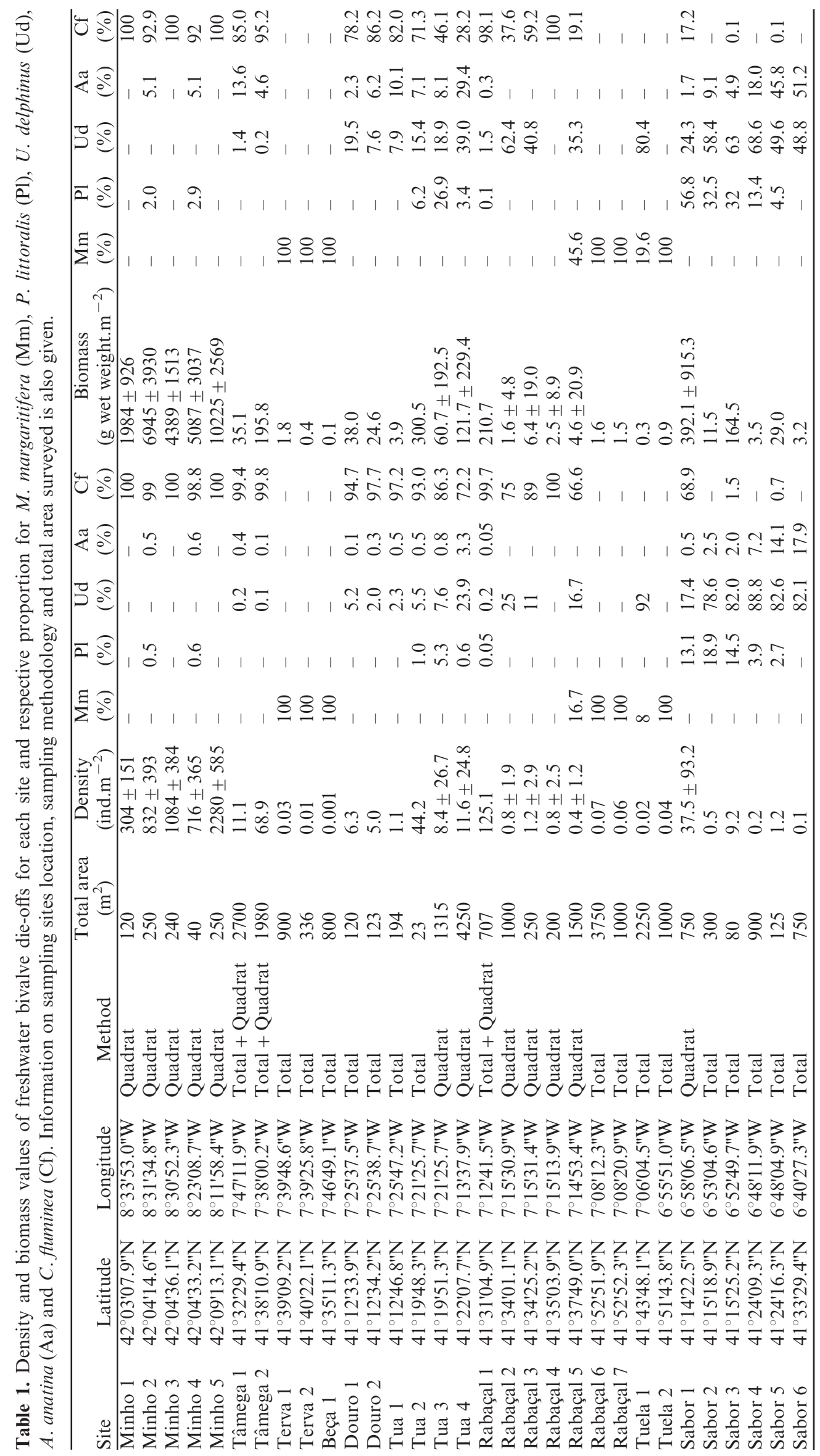



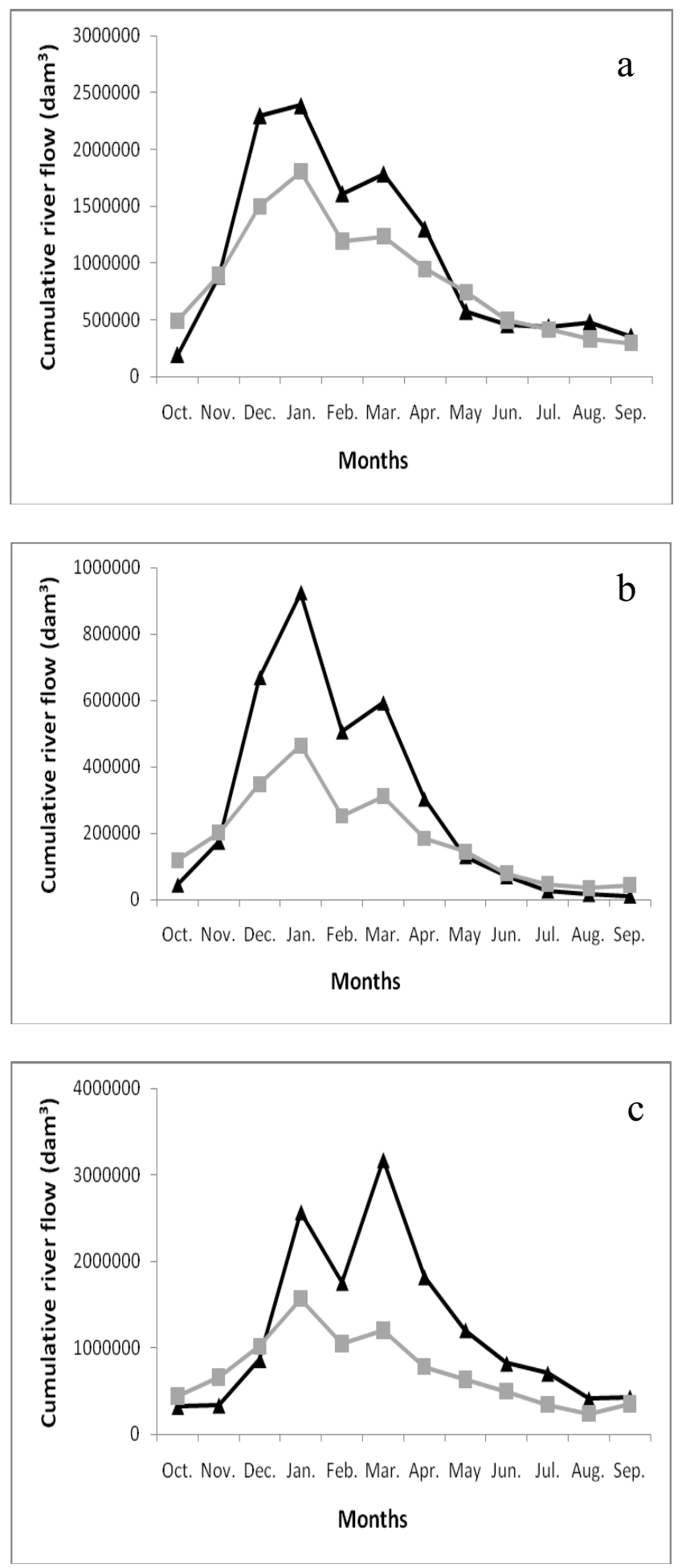

Fig. 2. Cumulative river flow values for the (a) River Minho measured at Foz do Mouro, (b) River Tâmega measured at Torrão and (c) River Douro measured at Pocinho. Black lines represent cumulative river flow values measured from October 2009 to September 2010 and grey lines represent mean values from 1990 to 2010 .

species (A. anatina, C. fluminea and P. littoralis), three species on the River Douro (A. anatina, $C$. fluminea and $U$. delphinus), four species on the River Tâmega (all species
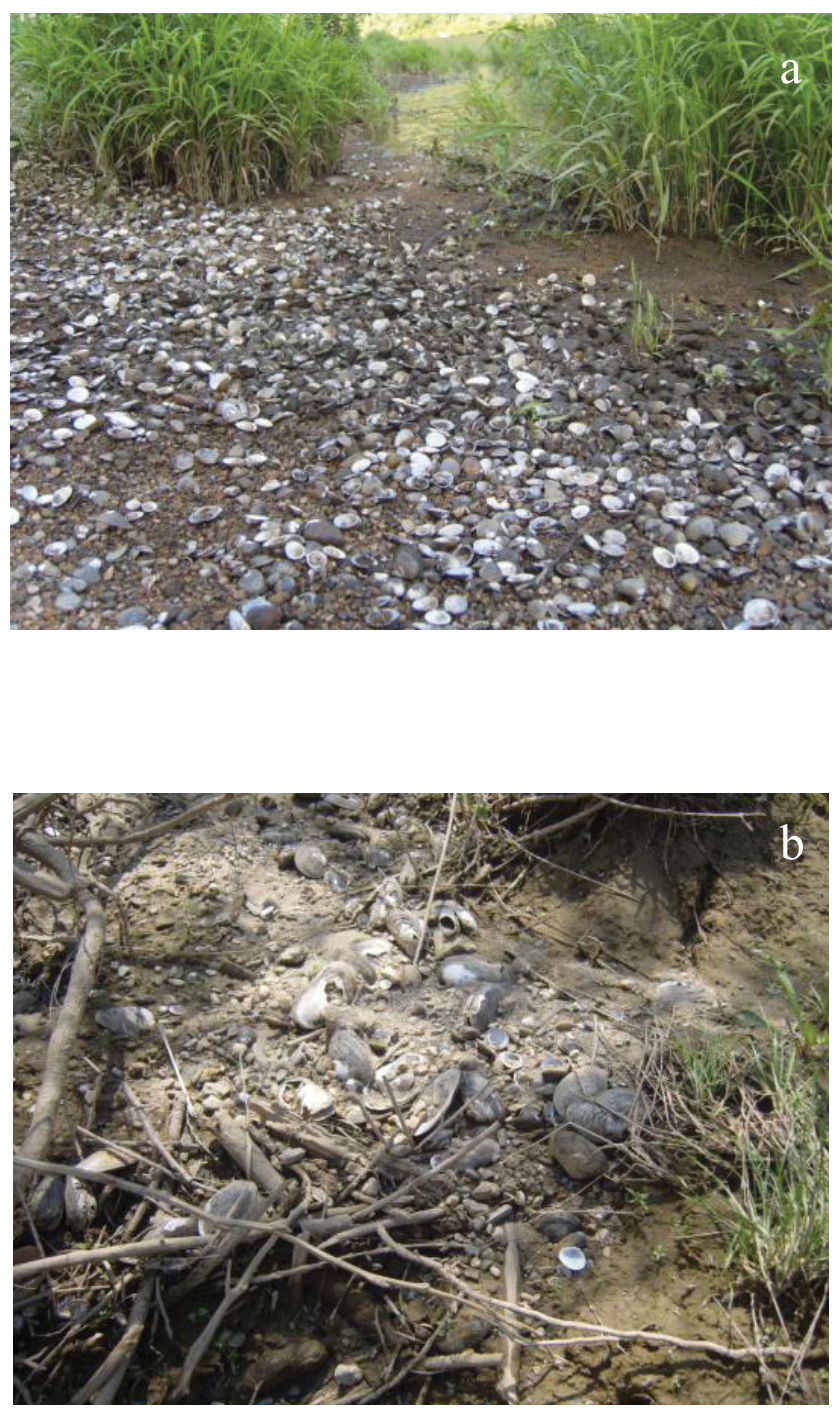

Fig. 3. Photos showing massive mortalities at (a) Minho site 5 with a great accumulation of $C$. fluminea shells and (b) Sabor site 1 with the accumulation of $C$. fluminea, $P$. littoralis and U. delphinus shells.

except $P$. littoralis), five species on the River Tua and four species on the River Sabor (all species except M. margaritifera). There were clear differences in the species composition between the five different river basins (ANOSIM $R=0.27 ; P<0.05$ ). There were also clear differences along the longitudinal profile, in particular for the Rivers Tua and Sabor (Tab. 1).

Table 1 summarizes the density, biomass and distribution of dead bivalves collected from the five river basins. Higher densities were collected in the River Minho, with the highest density occurring at site $5\left(2280\right.$ ind. $\left.\mathrm{m}^{-2}\right)$; the invasive species $C$. fluminea clearly predominated. The lowest densities occurred in the Rivers Terva and Beça (tributaries of the River Tâmega), Rabaçal sites 6 and 7 and Tuela sites 1 and 2 (tributaries of the River Tua). The lowest overall observed density was at Beça site 1 (0.001 ind. $\mathrm{m}^{-2}$ ). Sites with lower density were dominated by the presence of M. margaritifera (with the exception of Tuela 1 
where $U$. delphinus also occurred). C. fluminea was clearly the densest species and was present at 21 sites $(68 \%$ of all sites surveyed). Biomass values followed similar trends as density; the highest values occurred on the River Minho with maximum biomass at Minho site $5(10225 \mathrm{~g}$ wet weight. $\left.\mathrm{m}^{-2}\right)$ and a minimum at Beça site $1(0.1 \mathrm{~g}$ wet weight. $\mathrm{m}^{-2}$ ). Again, $C$. fluminea was the species with the highest biomass, although the dominance was not as strong as with the density results (Tab. 1).

\section{Discussion}

The severe winter of 2009/2010 resulted in higher river flows compared to mean values recorded over the last 20 years in Northern Portuguese rivers. The higher flows provoked mass movement of sediments, uprooted trees and affected riparian vegetation. The high river flows also resulted in the movement of live bivalves from the riverbed, where they normally live partially buried in the sediment with the posterior part of their shells exposed to the water column, dislodging and depositing them on the stream banks.

Even in normal hydrological years, it is not unusual to find dead freshwater bivalves on riverbanks but the numbers reported in this study are clearly exceptional. Although some studies show that several species manage to avoid the major effects of floods by sheltering behind rocks and boulders or burrowing deeper into the sediments, such strategies may be impossible when large flood events occur (Hastie et al., 2001). The results of this study show that a large quantity of freshwater bivalves were transported and stranded on the riverbanks where they subsequently died due to desiccation when the water level returned to normal levels during May. Such a situation is expected, due to the low locomotion capability of these species (Vaughn and Taylor, 1999). Unfortunately, our data could not assess the percentage of individuals removed from the water to the riverbanks since earlier density and biomass data from the survey sites were unavailable. According to Hastie et al. (2001), 4-8\% of the $M$. margaritifera population were killed during a major flood in the River Kerry (Scotland). Applying such findings to our results it was also possible that the higher river flows during 2009/2010 resulted in higher mortalities, negatively affecting bivalve populations and possibly imposing a serious threat to some species. C. fluminea, has a typical opportunistic life cycle (Sousa et al., 2008b, 2008d, 2008e) giving this species an advantage over the four native species concerning extreme climatic events, since it recovers more rapidly (Sousa et al., 2008a, 2008c; Ilarri et al., 2011). Extreme events are predicted to increase over the next few decades as a result of climate change. Thus, the resilience of the different species should be studied to assess resulting ecological alterations. In addition, some native freshwater bivalve species, such as $M$. margaritifera and $P$. littoralis, have high conservation status; findings from such mortality events should be incorporated into management plans and selected restoration measures such as rapid relocation of endangered native mussels back to the riverbed can be easily applied to lessen possible impacts. However, the construction of several large hydroelectric dams is already underway or due to begin very soon in the Rivers Tâmega, Tua and Sabor. The impact of these infrastructures will impose an additional threat that may outweigh the impacts of floods to these native populations.

Our results showed that mortality rates differed between sites and river systems, reflecting spatial distribution patterns and habitat preference of the freshwater bivalve species under study. However, other factors such as the characteristics of each catchment and the different river flow levels acting at the local scale may contribute to the different values of density and biomass found on the riverbanks.

The most important result of this study is the possible fundamental role of these die-offs as a resource pulse on adjacent terrestrial areas. Recent studies in food web dynamics emphasize the importance of spatial subsidies, in particular, the significance of the link between different habitats via the flow of nutrients, energy and materials (Polis et al., 1997; Maron et al., 2006). One possible cause of resources pulses are climatic or environmentally driven events (e.g., El Niño Southern Oscillation; unusual precipitation patterns combined with increased erosion). The extremely high density and biomass transferred to the riverbanks, highlights bivalves as a major resource pulse of considerable amounts of nutrients and energy to the adjacent terrestrial food web. Resource pulses are defined as episodes of low frequency (rarity), large magnitude (intensity) and short duration (brevity) that result in increased resource availability in space and time, but subsequently decay in temporal availability (Yang et al., 2008). In our study, we can conclude that the $2009 / 2010$ floods were not frequent events when compared with results from the 20-year dataset, that the density and biomass levels removed through bivalves die-off were very high and the resources were only available for short periods of time (at least for the surface-dwelling consumers).

Theoretically, resource pulses can affect consumer responses at both individual and population levels, and can also be responsible for indirect effects at community and ecosystem levels (Yang et al., 2008). The bivalve mortality reported in this study resulted in high-quality carrion, a vital resource pulse available across different trophic levels. This biomass can be consumed by widespread generalists, relatively specialized and highly mobile consumers and detrital consumers (Ostfeld and Keesing, 2000; Yang, 2004). Widespread generalist consumers with relatively non-selective diets can exploit bivalve carrion when it becomes available. In this study, ant, beetle, spider, mammal and bird species were observed to consume bivalve carrion (Sousa, personal observation). However, relatively specialized and highly mobile consumers, capable of travelling long distances can also consume bivalve carrion. Thus, the availability of bivalve carrion can act as a driver of numerical changes due to 
behavioural aggregative responses, increases in reproductive rates or the combination of both processes (Yang et al., 2008). The availability of bivalve carrion can initiate effects across multiple trophic levels, since the increase in resources will increase the density of one consumer which may become a secondary resource pulse for consumers at higher trophic levels. Considering that the biomass resulting from these mortalities may be quite high, it is possible that this resource pulse may be a surplus to predators and other surface-dwelling consumers. As a result, a considerable amount of this biomass can enter the detrital food web driving changes in microbial biomass and nutrient cycles (Yang, 2004). Future studies should include the influence of this situation on plant growth and nutrient cycles, including the availability of calcium derived from bivalve shells.

It was not the aim of this study to assess how this subsidy influences the structure and dynamics of the recipient food web. However, given the quantity of biomass removed, we believe that this situation deserves future attention. Our results support the growing body of evidence indicating that terrestrial food webs adjacent to rivers can be strongly subsidized by the movement of nutrients and energy from adjacent riverbed onto less productive land, which are often also subject to harsher conditions (Ben-David et al., 1998; Helfield and Naiman, 2001). Although, some examples have been reported on migratory fishes, this study emphasizes the possible fundamental role of freshwater bivalves. It is also important to note that invasive species such as $C$. fluminea could become a significant fraction of bivalve die-off resource pulses and this situation should be taken in account in aquatic ecosystems already affected by this and other invasive bivalves (e.g., Dreissena polymorpha and Limnoperna fortunei) that could attain high biomass and are subject to frequent massive mortalities.

\section{Conclusion}

Floods are fundamental elements in the natural cycles and often impact key natural components such as macroinvertebrates, fishes and riparian vegetation. However, the possible importance of floods as drivers of resource pulses through freshwater bivalve die-offs is poorly studied in freshwater ecology. The findings of this study emphasize the importance of the availability of this carrion source to consumers (directly consuming these bivalves as prey or indirectly as a source of dead organic material). The influence of climate change on such resource pulses is of particular interest due to the predicted increase in climatic variability (e.g., more frequent and intense extreme climatic events). The further study of such changes will be particularly important in areas of interface between aquatic and terrestrial ecosystems (Yang et al., 2008). Freshwater bivalves are one of the faunal groups exhibiting an accelerated rate of extinction; thus, the impacts of floods should be considered more widely in future ecological and conservational studies.
Acknowledgements. The authors thank Ana Claro, Carina Sobral, Maria Parada, Mariana Hinzmann, Mónica Nogueira, Patrícia Ramos, Telmo Fonseca and Tiago Ascensão for valuable help during the field campaigns and William G. McDowell for valuable suggestions on the manuscript. This study was conducted in the scope of the project "NISTRACKS", funded by the Portuguese Foundation for the Science and the Technology (contract: PTDC/AAC-AMB/102121/2008) and COMPETE funds.

\section{References}

Adis J. and Junk W.J., 2002. Terrestrial invertebrates inhabiting lowland river floodplains of Central Amazonia and Central Europe: a review. Freshw. Biol., 47, 711-731.

Anderson W.B., Wait D.A. and Stapp P., 2008. Resources from another place and time: responses to pulses in a spatially subsidized system. Ecology, 89, 660-670.

Baxter C.V., Fausch K.D. and Saunders W.C., 2005. Tangled webs: reciprocal flows of invertebrate prey link streams and riparian zones. Freshw. Biol., 50, 201-220.

Ben-David M., Hanley T.A. and Schell D.M., 1998. Fertilization of terrestrial vegetation by spawning Pacific salmon: the role of flooding and predator activity. Oikos, 83, 47-55.

Burdon F.J. and Harding J.S., 2008. The linkage between riparian predators and aquatic insects across a streamresource spectrum. Freshw. Biol., 53, 330-346.

Clarke K.R. and Warwick R.M., 2001. Change in Marine Communities: An Approach to Statistical Analysis and Interpretation (2nd edn,), PRIMER-E Ltd, Plymouth Marine Laboratory, Plymouth.

Dodds W.K., 2002. Freshwater Ecology: Concepts and Environmental Applications. Academic Press, London.

Gende S.M., Edwards R.T., Willson M.F. and Wipfli M.S., 2002. Pacific salmon in aquatic and terrestrial ecosystems. BioScience, 52, 917-928.

Gratton C. and Vander Zanden M.J., 2009. Flux of aquatic insect productivity to land: comparison of lentic and lotic ecosystems. Ecology, 90, 2689-2699.

Hastie L.C., Boon P.J., Young M.R. and Way S., 2001. The effects of a major flood on an endangered freshwater mussel population. Biol. Conserv., 98, 107-115.

Helfield J.M. and Naiman R.J., 2001. Effects of salmon-derived nitrogen on riparian forest growth and implications for stream productivity. Ecology, 82, 2403-2409.

Hering D., Gerhard M., Manderbach R. and Reich M., 2004. Impact of a 100-year flood on vegetation, benthic invertebrates, riparian fauna and large woody debris standing stock in an alpine floodplain. River Res. Appl., 20, 445-457.

Holt R.D., 2008. Theoretical perspectives on resource pulses. Ecology, 89, 671-681.

Ilarri M., Antunes C., Guilhermino L. and Sousa R., 2011. Massive mortality of the Asian clam Corbicula fluminea in a highly invaded area. Biol. Invasions, 13, 277-280.

Ilg C., Foeckler F., Deichner O. and Henle K., 2009. Extreme flood events favour floodplain mollusc diversity. Hydrobiologia, 621, 63-73.

Lytle D.A. and Poff N.L., 2004. Adaptation to natural flow regimes. Trends Ecol. Evol., 19, 94-100. 
Maron J., Estes J., Croll D., Danner E., Elmendorff S. and Buckelew S., 2006. An introduced predator alters Aleutian Island plant communities by thwarting nutrient subsidies. Ecol. Monogr., 76, 3-24.

Ostfeld R.S. and Keesing F., 2000. Pulsed resources and community dynamics in terrestrial ecosystems. Trends Ecol. Evol., 15, 232-237.

Polis G.A., Anderson W.B. and Holt R.D., 1997. Toward an integration of landscape and food web ecology: the dynamics of spatially subsidized food webs. Annu. Rev. Ecol. Syst., 28, 289-316.

Romanuk T.N. and Levings C.D., 2010. Reciprocal subsidies and food web pathways leading to chum salmon fry in a temperate marine-terrestrial ecotone. PLoS One, 5, e10073.

Sousa R., Rufino M., Gaspar M., Antunes C. and Guilhermino L., 2008a. Abiotic impacts on spatial and temporal distribution of Corbicula fluminea (Müller, 1774) in the River Minho estuary, Portugal. Aquat. Conserv., 18, 98-110.

Sousa R., Antunes C. and Guilhermino L., 2008b. Ecology of the invasive Asian clam Corbicula fluminea (Müller, 1774) in aquatic ecosystems: an overview. Ann. Limnol. - Int. J. Lim., $44,85-94$.

Sousa R., Dias S., Guilhermino L. and Antunes C., 2008c. Minho River tidal freshwater wetlands: threats to faunal biodiversity. Aquat. Biol., 3, 237-250.

Sousa R., Nogueira A.J.A., Gaspar M., Antunes C. and Guilhermino L., 2008d. Growth and extremely high production of the non-indigenous invasive species Corbicula fluminea (Müller, 1774): possible implications for ecosystem functioning. Estuar. Coast. Shelf Sci., 80, 289-295.
Sousa R., Dias S., Freitas V. and Antunes C., 2008e. Subtidal macrozoobenthic assemblages along the River Minho estuarine gradient (north-west Iberian Peninsula). Aquat. Conserv., 18, 1063-1077.

Strayer D.L., 2006. Challenges for freshwater invertebrate conservation. J. N. Am. Benthol. Soc., 25, 271-287.

Strayer D.L., Hunter D.C., Smith L.C. and Borg C.K., 1994. Distribution, abundance, and roles of freshwater clams (Bivalvia, Unionidae) in the freshwater tidal Hudson River. Freshw. Biol., 31, 239-248.

Strayer D.L., Downing J.A., Haag W.R., King T.L., Layzer J.B., Newton T.J. and Nichols S.J., 2004. Changing perspectives on pearly mussels, North America's most imperilled animals. BioScience, 54, 429-439.

Vaughn C., 2010. Biodiversity losses and ecosystem function in freshwaters: emerging conclusions and research directions. Bioscience, 60, 25-35.

Vaughn C. and Taylor C.M., 1999. Impoundments and the decline of freshwater mussels: a case study of an extinction gradient. Conserv. Biol., 13, 912-920.

Ward J.V., 1998. Riverine landscapes: biodiversity patterns, disturbance regimes, and aquatic conservation. Biol. Conserv., 83, 269-278.

Wetzel R.G., 2001. Limnology: Lake and River Ecosystems. Academic Press, London.

Yang L.H., Bastow J.L., Spence K.O. and Wright A.N., 2008. What can we learn from resource pulses? Ecology, 89, 621634.

Yang L.H., 2004. Periodical cicadas as resource pulses in North American forests. Science, 306, 1565-1567. 